\title{
DEVELOPMENT OF KNIFE EYES ON THE MAKING PROCESS OF ORGANIC BURNING PROCESS OF 7 LITERS FOR UMKM
}

\author{
Ahmad Yunus Nasution \\ Fakultas Teknik Universitas Muhammadiyah Jakarta \\ Jalan Cempaka Putih Tengah 27 Jakarta Pusat 10510, Tlp 021-4244016,4256024 \\ Email: ahmad.yunus@ftumj.ac.id
}

\begin{abstract}
The planning and design of the blades mixer for the organic slurry dough mixer is the application of the sciences obtained in real college. The main purpose of making blades mixer for this slurry dough mixer is to get an effective, efficient blades mixer design and higher quality organic slurry. With the making of this blades mixer, it is expected to contribute positively in the middle industry engaged in the food industry. The author designed several forms of modeling of blades mixer capable of stirring the organic pulp mixture with a capacity of 7 liters. The blades mixer are planned to use 304 steinless steel Austenitic material. For a planned blades mixer rotation of $35 \mathrm{rpm}$, and to achieve such a large rotation, pulleys and gearboxes (reducers) take an important role to achieve the planned rotation. The treatment carried out for this organic slurry dough mixer can be in the form of planned and unplanned treatments. With this report, it is expected to be able to add knowledge in the field of engineering.
\end{abstract}

Keywords : blades mixer, organic slurry mixture, organic slurry dough mixer

\section{INTRODUCTION}

The growing age of more and more new tools created to facilitate human work. One example is an organic slurry dough mixer for home industry, where this tool serves to ensure the quality of the slurry is evenly mixed according to the desire when it is being cooked.

The problem faced in the home industry of making organic pulp now is the quality of the slurry produced. There are still many shortcomings in the results of cooked porridge. Among them is the porridge produced still smells of burnt and the texture of the slurry becomes too thick which is caused by still using manual stirring so that it is not evenly distributed.

Therefore, the author plans and designs several forms of modeling of stirring blades for organic slurry dough mixing machines with a capacity of 7 liters. Then it will be calculated and analyzed using software solidworks to find out which modeling of the stirrer blade is the most effective so that it can produce slurry with the desired quality and is able to meet consumer needs.

\section{Literature Review}

As a research reference material, it is necessary to have literature study material related to this research, while the literature study which is the reference of the author is as follows:

\section{Organic Porridge}

Porridge is a soft textured food that is usually made from cooked rice for a long time so that the testicles become soft and easy to consume, both consumed by children and adults.

Good porridge is a slurry that contains lots of vitamins, fiber, protein, and also carbohydrates that are good for body health. Porridge with such content is found in porridge made from vegetables, fruits, and also organic based slurry such as brown rice and green 
beans, this is what is meant by Organic Porridge.

Organic porridge is very important to be consumed by toddlers over 6 months, because organic porridge is the best breast milk substitute because it contains good properties for toddler growth and can meet the toddler's daily needs. Organic porridge is also very good to be consumed by people who are sick who in fact should not consume food that is made from coarse ingredients.

\section{Mixer (Agitator)}

Complaints are operations that create movement in the stirred material. The purpose of the main stirring operation is before mixing. Mixing that can be used by the stirring process. In order to be able to optimize the most optimal mixing type (agitator) is needed. Mixers that must be in accordance with the desired mixing purpose. The following are various types of stirrers that can be used in the stirring process:

1. Propeller Type Agitators

2. Turbine type agitators

3. Paddle Type Agitators

4. Hellical-Ribbon type agitator

5. Anchor type agitators

6. Gate type agitators

7. Agitator type Saw blade

8. UZ type agitators

9. Coaxial type agitator

10. Hydrofolis type agitator

\section{Solidworks}

Solidworks is software engineering design especially 3D design models produced by DASSAULT SYSTEMES. This software is usually used in designing 3D models and there are 3 views in solidwork namely part to draw the model then assembly which is to assemble or combine part model models that we have described into a construction that we want and then the drawing is to draw / present part models or assembly that we have made to be forwarded into worksheets that are ready to print / print and forwarded to the industry.

In addition Solidworks can also analyze the models that have been made. That is, such as stress analysis (stress), strain (strain), displacement, and getting a factor of safety.

\subsection{Stainless Steel Austenitic 304}

Austenitic has chrome content in the range of $17 \%-25 \%$ and Nickel in the range $8-20 \%$ and some additional elements / elements in an effort to achieve the desired nature. This group's stainless steel is non magnetic.

304 Stainless Steel is a very good quality material as household appliances or food industry equipment

This is what makes Stainless Steel 304 the most versatile and most widely used stainless material. Why is Stainless Steel 304 better than the

others?

The reason is, because the shape and end result in stainless steel 304 work is much better and neat than other stainless steel. This is due to the fact that stainless steel 304 has easy shape characteristics when welded.

Therefore, it is very important before making a stainless steel product or buying a stainless product, make sure it is made of 304 stainless. 304 stainless material is often used by large companies in the country, for example for food pan, grease trap, steamer, gas oven burner and others other. 
Tabel 2.1 Austenitic stainless steel composition 304

\begin{tabular}{|c|c|c|c|c|c|c|c|}
\hline \multicolumn{8}{|c|}{ ASME SA240 304 Chemical Composition } \\
\hline \multirow{2}{*}{ Grade } & \multicolumn{7}{|c|}{ The Element Max (\%) } \\
\hline & C & Mn & $P$ & S & $\mathrm{Si}$ & $\mathrm{Cr}$ & $\mathrm{Ni}$ \\
\hline \multirow{3}{*}{$\begin{array}{l}\text { ASME } \\
\text { SA24 } \\
0304\end{array}$} & $\begin{array}{l}0.0 \\
5\end{array}$ & 2.0 & $\begin{array}{l}0.0 \\
45\end{array}$ & $\begin{array}{l}0.0 \\
30\end{array}$ & $\begin{array}{l}0.7 \\
5\end{array}$ & $\begin{array}{l}18.0- \\
20.0\end{array}$ & $\begin{array}{l}8.0- \\
10.5\end{array}$ \\
\hline & Mo & $\mathrm{N}$ & $\begin{array}{l}C \\
u\end{array}$ & & & & \\
\hline & & 0.10 & & & & & \\
\hline
\end{tabular}

\section{METHODS}

The method used in the planning and design of the stirring blades for this slurry dough mixer uses an analysis method with software solidworks. In the initial stages several modeling will be made and then analyzed to determine which mixer blade is more efficient and effective for stirring. The design of the stirring blades for the slurry mixing machine is carried out with the following stages:

\section{Literature Study}

Literature study consists of literature review, namely reference sources obtained from previous research. Theoretical basis is reference sources obtained from books and web related to the stirrer of the slurry mixture.

\section{Designing a Variety of Stirring Blade Eyes}

Make several modeling variations of stirring blades using Solidworks Software. Beginning with planning and design to determine several modeling variations of the stirring blades.
3. Analysis of Modeling Variations in Stirring Blade Eyes

Several variations of the modeling of the stirring blades that have been made will be analyzed using Solidworks software. Among them will be carried out analysis of Strain, Stress, Displacement, Deformation, and Factor of Safety. Then from the results of the analysis will be obtained one of the best variations of stirring blades to use.

\section{Creation of a Stirring Blade}

Starting from the selection of tools and material materials, then proceed with the process of making a stirring blade from the results of the previous analysis.

\section{Data Testing and Retrieval}

Test the stirring blades to stir the organic pulp mixture with a capacity of 7 liters when cooked. Then take data from the results of the test.

\section{Results and Discussion}

From the results of data collection after testing, conclusions and suggestions will be made for future improvement.

\section{Report writing}

Writing or composing from the beginning to the end of the research is expected that this writing can make it easy for readers to understand. 


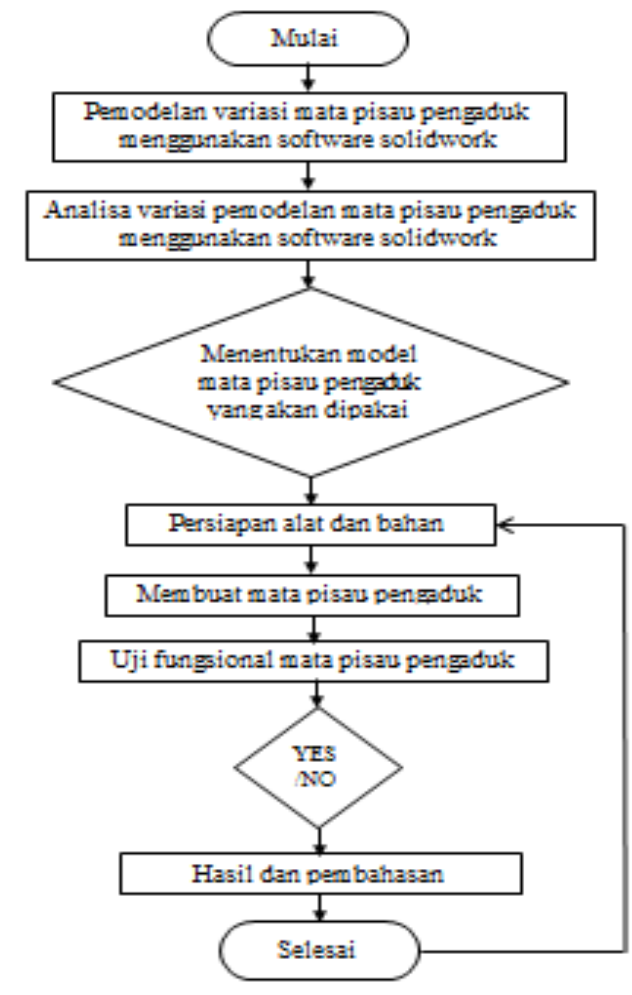

Gambar 3.1 Research flow chart

\section{RESULT}

\subsection{Designing the Design of the Mixer Blades}

Below are some designs of stirring blades for organic slurry dough mixing machines that have been drawn using solidworks software:

1. Design of the 1 st mixer blade

Design the first slurry stirrer blade using the Hellical stirrer type - Ribbon. Hellic / spiral shape is intentionally not made like a screw thread in general, but is made intermittently between each hellical at a distance of $65 \mathrm{~mm}$ and has three hellic plates with a diameter of $340 \mathrm{~mm}$ hellic with a Hellic slope angle of $30^{\circ}$. The use of a $30^{\circ}$ angle is the assumption that the slurry mixture can be evenly mixed. The material used is austenitic 304 stainless steel with a thickness of $2 \mathrm{~mm}$. As in Figure 4.1.

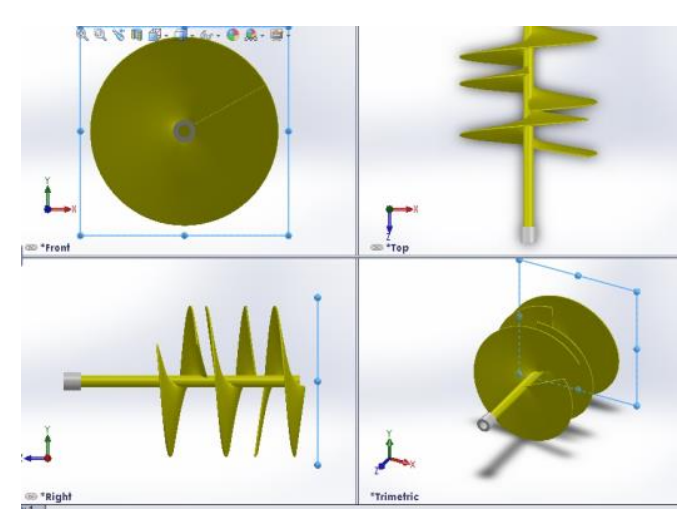

Gambar 4.1 Design of the 1st mixer blade

2. Design of the 2 nd mixer blade

The design of the second slurry dough mixer uses Paddle stirrer type. Has 4 levels of stirring blades with a diameter of $340 \mathrm{~mm}$ with a height of $75 \mathrm{~mm}$ per paddle. Has a distance between each $10 \mathrm{~mm}$ paddle, as described in Figure 4.2.

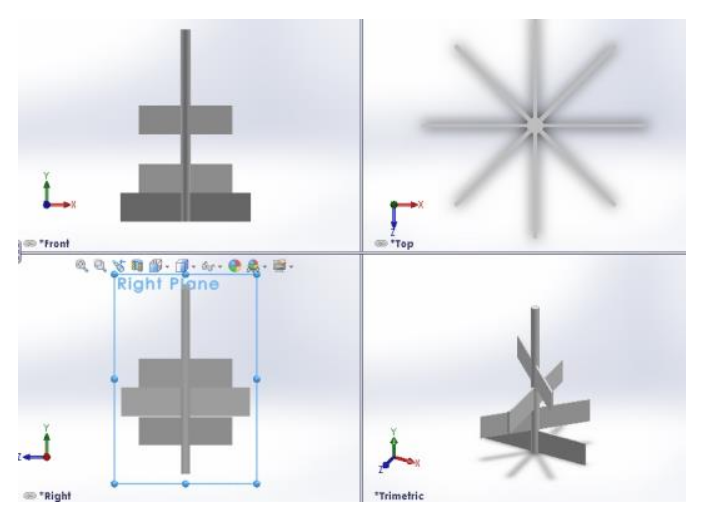

Gambar 4.2 Design of the 2nd mixer blade

3. Design of the 3rd mixer blade 
The design of the third slurry stirrer blade uses the UZ type stirrer. It has 4 levels of stirring blades and the material used is austenitic 304 stainless steel with a thickness of $2 \mathrm{~mm}$. Has a distance between each mixing blade $10 \mathrm{~mm}$.

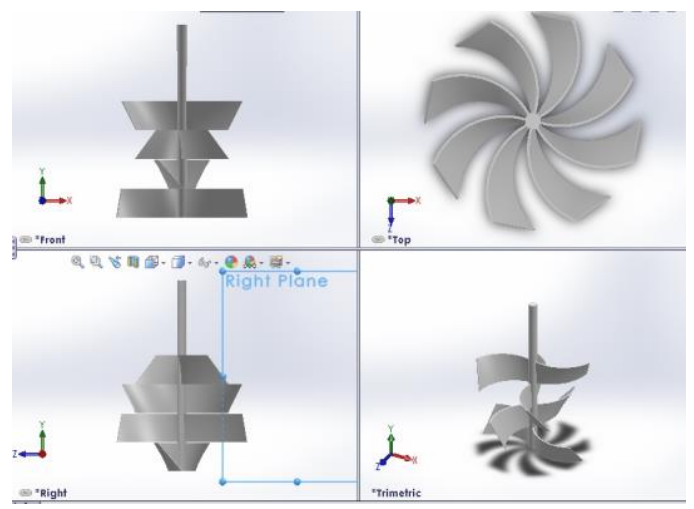

Gambar 4.3 Design of the 3rd mixer blade

\subsection{Analysis results}

After drawing the three designs of the stirring blades, then analyzing using solidworks software, the analysis includes Stress, Strain, and Displacement, is attached in Appendix A. Furthermore, the results of the analysis of the three designs of the stirring blades will be displayed using graphs. Following Figure 4.4. is a Stress and Displacement comparison chart, with nodes from the three organic slurry mixers.

Note: Numbering at the point of the graph shows the results of the analysis of each design of the stirrer blade.

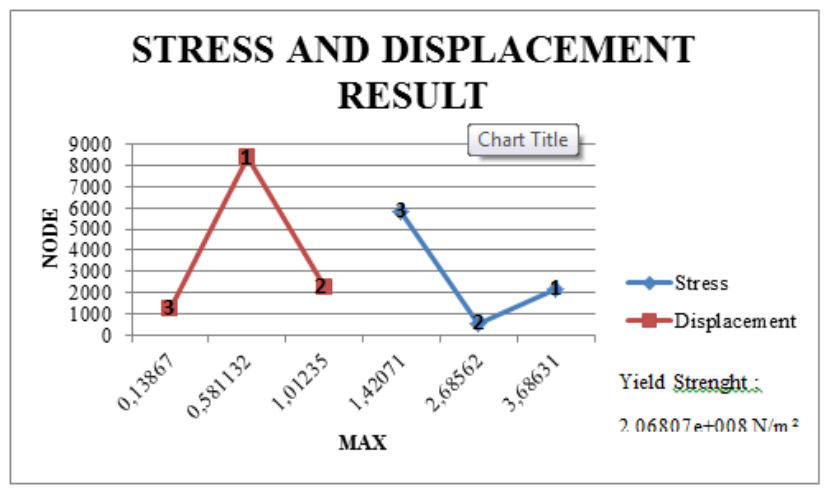

Gambar 4.4. Stress and Displacement comparison chart of the three mixing blades

Following Figure 4.5. is a comparison chart of Strains with Part Elements from the three designs of the organic baby slurry mixture.

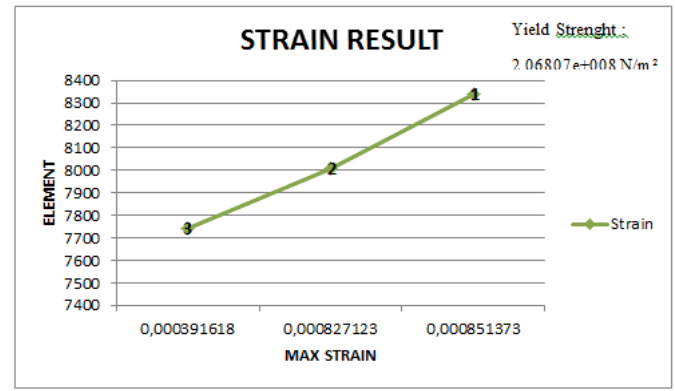

Gambar 4.5. Strain comparison chart of the three mixing blades

\subsubsection{Calculation of Analysis Results}

- Stress Calculation (Voltage)

$$
\sigma=\frac{F}{A}
$$

Information:

F: large press / pull force $(\mathrm{N})$

A: cross sectional area $(\mathrm{m} 2)$

$\sigma:$ voltage $(\mathrm{N} / \mathrm{m} 2)$ 
Known:

$$
\begin{aligned}
& \mathrm{F}=280,3584 \mathrm{~N} \\
& \mathrm{~A}=38,3 \mathrm{~m}^{2}
\end{aligned}
$$

Answer :

$$
\begin{aligned}
& \sigma=\frac{280,3584 \mathrm{~N}}{38,3 \mathrm{~m}^{2}} \\
& \sigma=7.3200 \mathrm{~N} / \mathrm{m}^{2}
\end{aligned}
$$

- Calculation of security factors $(\eta)=$ Sy / бe Where :

Sy $=$ Yield Strength. For Stirring Blade Eye Parts (1st, 2nd, and 3rd) Austenitic 304 Stainless Steel material Yield strength is known as $=2.06807 \mathrm{~N} / \mathrm{m} 2$

$\sigma \mathrm{e}=$ Maximum Von Mises voltage. In the stress analysis of Von Mises stress the 1st stirrer blade is known to be $3.68631 \mathrm{~N} / \mathrm{m} 2$ Then: $(\eta)=$ Sy $/ \sigma \mathrm{e}=$ $(2.06807 \mathrm{~N} / \mathrm{m} 2) /(3.68631 \mathrm{~N} / \mathrm{m} 2)=$ 0.5610

$\sigma \mathrm{e}=$ Maximum Von Mises voltage. In the stress analysis of Von Mises stress the second stirring blade is known to be $2.68562 \mathrm{~N} / \mathrm{m} 2$ Then: $(\eta)=\mathrm{Sy} / \sigma \mathrm{e}=$ $(2.06807 \mathrm{~N} / \mathrm{m} 2) /(2.68562 \mathrm{~N} / \mathrm{m} 2)=$ 0.7700

$\sigma \mathrm{e}=$ Maximum Von Mises voltage. In the stress analysis of Von Mises stress the 3rd stirrer blade is known to be $1.42071 \mathrm{~N} / \mathrm{m} 2$ Then: $(\eta)=$ Sy $/ \sigma e=$ $(2.06807 \mathrm{~N} / \mathrm{m} 2) /(1.42071 \mathrm{~N} / \mathrm{m} 2)=$ 1.4556

In the above analysis it is known that the smallest voltage occurs in the 1st Stirring Blade with Austenitic 304 Stainless Steel material. It can be concluded from the results above that the 1 st stirring blade is safe for use, because it produces a small safety factor at its minimum point .

\subsection{Making Helical Stirrer Blades - Ribbon}

The flow of the process of making the stirring blade is as follows:

1. The process of cutting three pieces of stainless steel into a circle with a diameter of $340 \mathrm{~mm}$.

2. After that the three stainless steel plates that have been shaped like a circle were cut to the size of $170 \mathrm{~mm}$ fingers.

3. Then after cutting the three plates are bent to form a helix with a slope angle of $30^{\circ}$.

4. Then the process of connecting between three stainless steel rods and using the electric welding method with a distance between each helix plate is $65 \mathrm{~mm}$. The following picture 4.6 is the result of the connection process between the plate hellic and the shaft of the stirring shaft.

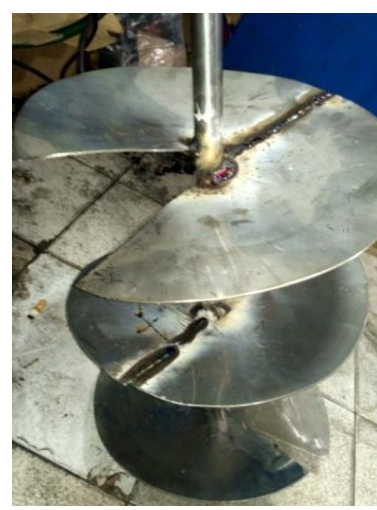

Gambar 4.6 Mixer blades after going through the welding process

5. After that, remove the remaining slag from the welding using a slag hammer / welding hammer. 
6. The final step is amplification and polishing with hand grinding. The final result as in Figure 4.1.

Following picture 4.7. is a stirring blade that has gone through all processes including polishing.

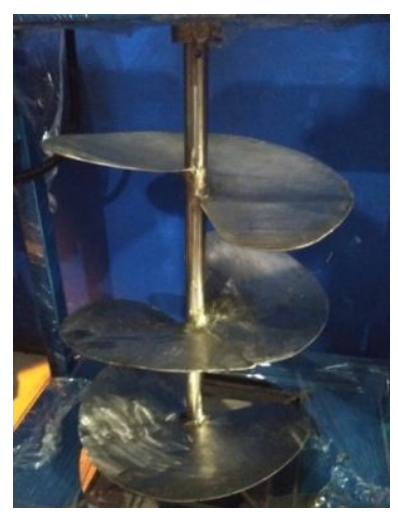

Gambar 4.7. Helical mixer blade - Ribbo

\section{CONCLUSION}

\section{Conclusions}

1. Material material used in the manufacture of stirring blades is Austenitic 304 Stainless Steel, in accordance with the standardization of BPOM (Food \& Drug Supervisory Agency in Indonesia), FSIS (Food Safety \& Inspection Service), and ASTM (American Society for Testing and Materials) .

2. The mixer blade design used is the Hellical-Ribbon type, with the value of $\max$ stress $=3.6863 \mathrm{~N} / \mathrm{m}^{2}$, strain $=$ 0.000851373 , displacement $=0.581132$ $\mathrm{mm}$ and the value of safety factor $=0.5610$

3. From the comparison results obtained the factor of safety value of the 3rd stirrer blade is higher than the others, namely $(\eta)$ $=1.4556$

4. From the calculation results, the stirring blades with von misses stress values approached $\sigma=7.3200 \mathrm{~N} / \mathrm{m} 2$ which is very good to use.
5. The results of the organic slurry being cooked and stirred using the type of the 1st stirring blade for the organic slurry dough mixer has a softer texture, the mixture is evenly mixed and not scented burnt compared to manual stirring.

\section{Suggestions}

1. The author hopes that SMEs (Small and Medium Enterprises) research and make observations that support the development of this food business on the market.

2. Please note when installing the shaft of the stirrer blade with the gearbox shaft always check the joint bolt on the joint, whether the shaft of the stirring blade is fastened and does not shake.

3. Also pay attention to the part of the locking bolt on both sides if it is installed properly. If it is not installed properly it can cause the pan to shift during the stirring process and cause the stirring blade to come into contact with the inside of the pan wall.

4. More attention to the "safety" side. Because to find out the organic baby porridge mixture is completely even or not, it is still taken a little with the hand when the stirring knife stops rotating within 10 minutes at each stirring pause.

5. Care and cleanse the stirring blades and containers before and after the cooking process.

\section{REFERENCES}

Aesteiron., Austenitic Stainless Steel Composition 304, http://www.aesteiron.com, 2014.

Green, B., What Is Organic Porridge?, http://bintaragreen.blogspot.com, 2015.

Hezim, F., Type - Type of Agitator (Mixer), http://faisolhezim1994.blogspot.com, 2014. 
Kurniawan, R., Stirring and Mixing, http://tekimku.blogspot.com, 2011. Kursus Cad., Software Solidworks, http://www.kursuscad.net, 2015.

Nata, R., Harry Brearley (1871 - 1948) Develop Stainless Steel, http://kabardewata.com, 2015
Saputra, R., Design of the Sala Lauak Dough Mixer Machine, Mechanical Engineering, 6364.

UnoCAD TC., Steps for Using Solidworks Simulation, http://unocadtc.blogspot.com, 2017. 